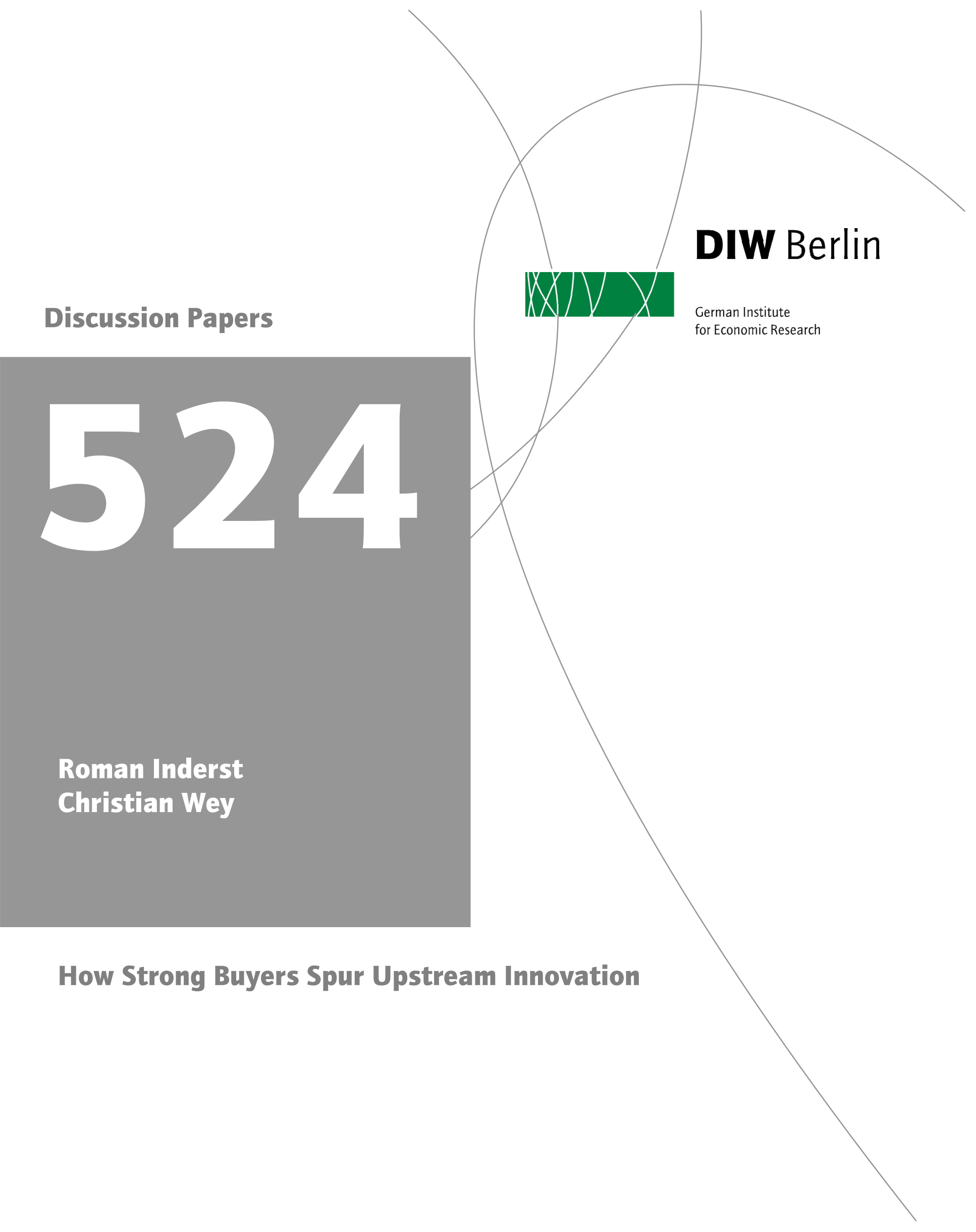

Berlin, November 2005 


\section{IMPRESSUM}

(C) DIW Berlin, 2005

\section{DIW Berlin}

German Institute for Economic Research Königin-Luise-Str. 5

14195 Berlin

Tel. +49 (30) $89789-0$

Fax +49 (30) 897 89-200

www.diw.de

ISSN print edition 1433-0210

ISSN electronic edition 1619-4535

\section{All rights reserved.}

Reproduction and distribution

in any form, also in parts,

requires the express written

permission of DIW Berlin. 


\title{
How Strong Buyers Spur Upstream Innovation*
}

\author{
Roman Inderst ${ }^{\dagger} \quad$ Christian Wey $^{\ddagger}$
}

First version Mai 2005; this version October 2005

\begin{abstract}
We challenge the view that the presence of powerful buyers stifles suppliers' incentives to innovate. Following Katz (1987), we model buyer power as buyers' ability to substitute away from a given supplier and isolate several effects that support the opposite view, namely that the presence of powerful buyers induces a supplier to invest more in cost reduction. In contrast to negotiations with smaller buyers, the outcome of negotiations with large buyers is fully determined by their more valuable alternative supply option. This increases the supplier's incentives to reduce marginal costs, both as the supplier receives a larger fraction of the thereby generated incremental profits and as this makes buyers' alternative supply option less valuable. The latter effect is due to downstream competition between buyers and, as we show, is also stronger the larger and thus the more powerful buyers are.
\end{abstract}

Keywords: Buyer Power; Merger; Investment Incentives.

\footnotetext{
*Roman Inderst acknowledges financial support from the ESRC grant on "Buyer Power in Retailing".

${ }^{\dagger}$ Corresponding author: London School of Economics, Department of Economics and Department of Finance, Houghton Street, London WC2A 2AE, UK. E-mail: r.inderst@lse.ac.uk.

${ }^{\ddagger}$ Deutsches Institut für Wirtschaftsforschung Berlin (DIW), Technische Universität Berlin, CEPR, London. E-mail: cwey@diw.de.
} 



\section{Introduction}

Any purely static view of how market structure affects welfare is likely to be misleading. Antitrust authorities are thus well advised to take a more dynamic perspective - as they increasingly do - and to take into consideration how market structure can affect firms' incentives to invest and innovate. Traditionally, the focus has been squarely on how horizontal market structure, namely the degree of horizontal competition and the market power exerted by individual firms, affects investment incentives. Lately, however, antitrust authorities around the world have become increasingly concerned about the exercise of buyer power in vertical relations.

Retailing, in particular in fast-moving consumer goods, provides a prominent example. There, the formation of multinational retail companies and the switch to ever larger store formats have arguably put increasing pressure on suppliers, as noted by a number of policy reports that were commissioned by antitrust authorities and policy institutes (e.g., OECD (1999), European Commission (1999), FTC (2001), and Competition Commission (2000) for the UK). ${ }^{1}$ One key concern is that the exercise of buyer power will invariantly stifle suppliers' incentives. ${ }^{2}$ Given the dearth of both theoretical and empirical work (see also the literature discussion below), the conjecture that buyer power is likely to negatively affect upstream incentives seems like a very reasonable first response. As we argue in this paper, it can, however, be extremely misleading.

The notion that buyer power reduces incentives seems to rest on the presumption that by extracting a larger share of total profits, a more powerful buyer can also extract a larger share of the incremental profits from an upstream investment, which should naturally reduce suppliers' incentives. ${ }^{3}$ A formal way to capture this presumption is to assume that a buyer can extract a fixed fraction of the joint profits and to account for varying degrees of buyer power by simply

\footnotetext{
${ }^{1}$ Though being a very prominent example, retailing in fast-moving consumer goods is not the only industry where such concerns have been expressed. Other examples include supply relations in the automotive industry or, in particular in the US, the health care industry.

${ }^{2}$ With regards to retailing, the view that "suppliers respond by under-investing in innovation or production" (FTC 2001, p. 57) when faced with stronger buyers seems to be pervasive. Pitofsky (1997) expresses similar concerns for the health industry. One possible countervailing force, though arguably only applicable to highly concentrated industries, is that the presence of dominant buyers can overcome free-rider problems. (See Fumagalli and Motta (2000) for an analysis how the presence of large buyers can stimulate upstream entry.)

${ }^{3}$ We restrict attention to investments where incentives can not be adequately provided through contractual means. Similar to much of the related literature, this may be the case as it is hard to specify the investment ex ante in sufficient detail. Likewise, with a large number of buyers free-rider problems may also limit the extent to which incentives can be provided through up-front multilateral contracts.
} 
scaling this fraction up or down. Though convenient and therefore often used as a modelling tool, to our knowledge there exists, however, no theory that would support such a hard-wired link between the fraction of surplus a buyer can extract and more fundamental characteristics that would contribute to "buyer power", such as a buyer's size.

We build a model where buyer power arises from first principles. Buyers that compete in a downstream market negotiate with a supplier over bilateral contracts, where we allow for twopart tariffs. ${ }^{4}$ Our focus will be on a supplier's incentives to invest in reducing marginal costs. Buyers have to incur costs so as to generate alternative supply options. Large buyers are able to distribute these costs over a larger number of units, while they also reap larger benefits from having lower purchasing costs per unit. The consequence of this is that when negotiating with the supplier, a large buyer will have potentially a more attractive and thus also more credible alternative supply option. While for small buyers the option of switching to another source of supply will have no impact on their contracts, for large buyers the opposite can be the case: the outcome of negotiations can be fully pinned down by the value of their respective alternative supply options. ${ }^{5}$ The latter is good news for the supplier's incentives, even though the supplier's total profits decrease in the presence of fewer but larger buyers.

The supplier's incentives increase for the following reasons. First, the supplier now receives a larger fraction of the incremental profits that are generated by its investment. Furthermore, the supplier has additional incentives as a decrease in marginal costs makes the buyers' alternative supply option less valuable, which in turn allows the supplier to extract even more of the generated profits. The latter effect is due to downstream competition between buyers. As lower marginal costs will lead to lower per-unit purchasing costs for all supplied firms, a buyer that chooses to switch to another source of supply will be more at a disadvantage vis-a-vis competing firms the more the supplier has invested to reduce marginal costs. We also find that this effect is stronger if buyers that are already large grow even further (e.g., by taking over other smaller or equally sized buyers).

\footnotetext{
${ }^{4}$ In the main part of the paper we adopt an axiomatic approach to bargaining (namely, the Nash solution), while in the Appendix we provide a foundation in a non-cooperative game.

${ }^{5}$ In the parlour of bargaining theory, we thus use the well-known "outside option principle." Seminal references for this are Shaked and Sutton (1984), where this principle is applied to worker-firm bargaining, Binmore, Rubinstein, and Wolinsky (1989), who analyze the role of outside options in different non-cooperative alternating-offer games, and Binmore, Shaked, and Sutton (1989), who also provide some experimental support.
} 
Our paper does not intend to provide a carte blanche for the creation and exercise of buyer power. Instead, we would like to emphasize the following implications of our results. First, our results show that buyer power need not invariably stifle investment by upstream firms. To the contrary, our arguments support also the opposite view that buyer power can induce more investment. Second, on a more general level our results show that it is essential to make precise what is meant by the creation and exercise of buyer power. In our model, it is buyers' size that translates into more attractive alternative supply options, which then influence the outcome of negotiations and thereby the supplier's incremental profits from making additional investments. Other ways of enhancing buyer power such as the creation of private-label goods in retailing or the adoption of specific purchasing techniques (e.g., the use of electronic buying platforms) may well have different implications.

There is a growing literature on buyer power. ${ }^{6}$ When dealing with the welfare consequences of the exercise of buyer power, almost all of these papers focus on the impact on prices, typically in a model where only linear prices are feasible. ${ }^{7}$ To our knowledge, there are only a few exceptions that consider the (dynamic) implications for investment incentives. Both Chen (2004) and Inderst and Shaffer (forthcoming) consider the impact of buyer mergers on product diversity. In Inderst and Wey (2004) a merger of buyers may induce suppliers to choose a less convex and potentially welfare improving production technology. In these papers, buyer power, i.e., the possibility of some (larger) buyers to extract a discount, has different origins than in the current model, where it is linked to buyers' outside option. Our approach follows closely Katz (1987), which deals with the impact of price discrimination on welfare. Other channels to create a link between, in particular, size and buyer power include risk aversion (e.g., Chae and Heidhues (2004), DeGraba (2003)), the role of "gatekeeping" in local markets (Mazzarotto (2003)), or collusion among suppliers (Snyder (1996)).

Finally, some of the more general insights on bargaining and incentives are shared with the recent literature on the hold-up problem. De Meza and Lockwood (1998) and Chiu (1998) show how results of the theory of ownership (see Hart (1995) for an overview) change if one adopts

\footnotetext{
${ }^{6}$ Snyder (2005) and Inderst and Shaffer (2005) provide recent surveys.

${ }^{7}$ Von Ungern-Sternberg (1996) is an early example of models that assume linear pricing in all relationship, while in Chen (2003) linear pricing is only assumed with respect to a fringe of small buyers. Still other papers focus exclusively on distributional issues and derive conditions for when downstream or upstream mergers are beneficial (e.g., Horn and Wolinksy (1988) or Chipty and Snyder (1999)).
} 
a bargaining concept that embodies the logic of the "outside option principle", as we do in the current paper. There are, however, numerous differences between this work and ours. In our model, a supplier negotiates with multiple buyers, which further compete on a downstream market. Also, we study the role of buyers' size and are interested in what impact it has on consumer surplus by affecting upstream investment incentives.

The rest of the paper is organized as follows. Section 2 presents the model and derives some preliminary results on the bargaining solution. Section 3 analyzes how the formation of larger and more powerful buyers affects investment incentives. Section 4 discusses and extends these results. Section 5 concludes. The proofs as well as the calculations for a numerical example are relegated to the Appendix. The Appendix contains as well a non-cooperative bargaining model that supports the axiomatic approach that is taken in the main part of the paper.

\section{The Model and Preliminary Analysis}

\subsection{The Industry}

We analyze the incentives of one supplier, $S$, to reduce costs. ${ }^{8}$ The supplier provides an input to an intermediary industry. Firms in the intermediary industry use the input from $S$ to produce a homogeneous final good. All firms in the intermediary industry have identical production functions. As in Katz (1987), we assume that firms transform one unit of the input into one unit of the output. ${ }^{9}$ Also following Katz (1987), we assume that these intermediaries compete in a number of independent markets. We allow for $N \geq 2$ independent markets, in each of which there are two competing firms active. The $2 N$ downstream firms are owned by a number $I \geq 2$ of intermediaries, to which we simply refer to as buyers. A given buyer $B^{i}$, where $1 \leq i \leq I$, can only own firms in separate markets. ${ }^{10}$ The number of firms $n^{i}$ that $B^{i}$ owns will be our measure of the buyer's overall size. As in Katz (1987), larger buyers will be able to extract a

\footnotetext{
${ }^{8}$ There is a large literature that considers incentives to reduce costs, though there the focus is typically on the nature and intensity of horizontal competition (e.g., Qiu (1997)) or its interaction with agency problems inside firms (e.g., Schmidt (1997)).

${ }^{9}$ Given symmetry of production functions, this specification is not important for our results. A natural example where this specification is reasonable is that of retailing.

${ }^{10}$ This rules out standard monopolization effects. It also allows us to treat all $N$ markets symmetrically, regardless of the number and size of buyers. Note also that $\sum_{i=1}^{I} n^{i}=2 N$ as there are two competing firms in each of the $N$ (sub-)markets.
} 
better deal from $S$. Our focus is on analyzing how the formation of more powerful buyers affects the investment incentives of $S$, where buyer power is derived endogenously from buyers' size.

In each independent market, downstream firms offer a homogeneous good and compete in quantities. All $N$ independent markets are symmetric. If in a given market one of the two active firms chooses the quantity $q$ and the other firm the quantity $\widehat{q}$, the first firm's revenues are given by $R(q, \widehat{q}):=q P(q+\widehat{q})$, where $P(\cdot)$ denotes the inverse demand. Supplier $S$ has constant marginal costs of production $c \geq 0$. It is convenient to assume that $P$ is twice continuously differentiable where positive. In line with much of the literature analyzing models of homogenous Cournot competition, we assume that standard stability conditions are satisfied and that best responses are downward sloping. With constant marginal costs, this is ensured by the following assumption, which we make explicit for future reference. ${ }^{11}$

Assumption 1. The inverse demand $P$ that characterizes the downstream markets satisfies $P^{\prime}<\min \left\{0,-q P^{\prime \prime}\right\}$ where $P$ is positive.

We will find that in equilibrium, $S$ supplies all buyers at a price that equals marginal costs c. (We formally introduce supply contracts further below.) Under Assumption 1, the Cournot game where two firms can procure at constant input prices equal to $c$ has a unique equilibrium. In this equilibrium, both firms produce the same quantity, which we denote by $q_{S}$. From our assumptions on differentiability and by Assumption 1, we further have that $q_{S}$ is continuously differentiable in $c$ (where $q_{S}>0$ ) with $d q_{S} / d c<0$.

\subsection{The Two Stages of the Model}

There are two stages in our model. In the first stage, supplier $S$ can choose a non-contractible action to reduce marginal costs. Subsequently, $S$ negotiates simultaneously with all buyers $i \in I$. We may think of a situation where the supply contracts for all buyers $B^{i}$ are up for renewal. Alternatively, our model may capture the introduction of a new product produced by $S .{ }^{12}$

In the first stage, $S$ can choose a reduction of marginal costs $\Delta_{S} \geq 0$ such that $c=\bar{c}-\Delta_{S}$, where $0 \leq \Delta_{S} \leq \bar{c}$, with $\bar{c}>0$. The associated costs, that are born by $S$ up-front, are given by

\footnotetext{
${ }^{11}$ See, for instance, Vives (1999).

${ }^{12}$ This could also justify why there is only a single (potential) supplier. Further below, we have more to say on the introduction of alternative suppliers.
} 
$K_{S}\left(\Delta_{S}\right)$, which is strictly increasing and satisfies $K_{S}(0)=0$. It is convenient to assume that $K_{S}$ is twice continuously differentiable and that its derivative satisfies $K_{S}^{\prime}(0)=0$ and $K_{S}^{\prime}\left(\Delta_{S}\right) \rightarrow \infty$ for $\Delta_{S} \rightarrow \bar{c}$. We want to make sure that production is always profitable in equilibrium. A sufficient condition for this is that there exists some $q>0$ such that $P(q)>\bar{c}$.

Negotiations take place in the second stage of the model. There, buyers and the supplier $S$ negotiate over an (only privately observed) two-part tariff of the form $t^{i}(q)=\tau^{i}+q w^{i}$. We find the use of non-linear (here, two-part) tariffs natural in a setting where contracts are freely determined in negotiations. ${ }^{13}$ Moreover, in equilibrium there will be no incentives to deviate from two-part tariffs. This would, for instance, not be the case if we restricted attention to linear contracts, as it is sometimes done in the literature. ${ }^{14}$ We postpone a further description of the bargaining and contracting game until the next section. The remainder of this section is dedicated to a formalization of buyers' alternative supply options.

As discussed in the Introduction, we capture buyer power via the attractiveness of buyers' alternative supply options, which will in turn depend on their respective size. Though our model allows for a broader interpretation, we closely follow Katz (1987) and specify that after disagreement with $S$ buyers have the option to integrate backwards. ${ }^{15}$ When switching away from $S$ and integrating backwards, $B^{i}$ must incur some fixed costs $F \geq 0$. In addition, $B^{i}$ can influence the constant marginal costs of its alternative supply option, which we denote by $c_{\text {Out }}^{i}$. Without additional expenditures, we have $c_{\text {Out }}^{i}=\bar{c}_{\text {Out }}$, which is the same for all buyers. By incurring the additional expenditure $K_{B}\left(\Delta_{B}^{i}\right)$ after breaking up negotiations with $S, B^{i}$ can reduce marginal costs to $c_{O u t}^{i}=\bar{c}_{O u t}-\Delta_{B}^{i}$, where $0 \leq \Delta_{B}^{i} \leq \bar{c}_{O u t}$, with $\bar{c}_{O u t}>0$. We specify that $K_{B}(0)=0$, while $K_{B}$ is twice continuously differentiable with $K_{B}^{\prime}(0)=0$ and $K_{B}^{\prime}\left(\Delta_{B}^{i}\right) \rightarrow \infty$ for $\Delta_{B}^{i} \rightarrow \bar{c}_{O u t}$. Below we specify a requirement on $\bar{c}_{O u t}$ and $K_{B}$ that ensures that regardless of a buyer's size, it will be mutually beneficial to come to an agreement with $S$.

\footnotetext{
${ }^{13}$ The contrasting case would be that where supply contracts are determined in a "market interface" that operates between suppliers and buyers (e.g., an organized commodity market). Simpler (linear) contracts according to which each unit is traded at the same price may prevail in such markets. See Inderst and Shaffer (2005) for a more detailed discussion of the difference between bilateral negotiations and the assumption of a "market interface" and the implications for the analysis of buyer power.

${ }^{14}$ In many industries the use of (often highly complex) non-linear contracts is pervasive, e.g., in retailing where contracts may include volume discounts, slotting fees or pay-to-stay fees, and so on. (Recent econometric studies by Bonnet, Dubois, and Simioni (2004) for bottled water in France and by Berto Villas-Boas (2004) for yoghurt in the U.S. also support the view that non-linear pricing is pervasive in retailing.)

${ }^{15}$ More specifically, the investment a buyer must make in order to successfully integrate backwards can also be interpreted as costly search for an alternative supplier.
} 
Note that it is only after disagreeing with $S$ that $c_{\text {Out }}^{i}$ will be determined. Consequently, the choice of the supplier's marginal costs $c$ in the first stage will affect the choice of $c_{\text {Out }}^{i}$ after $B^{i}$ failed to come to an agreement with $S$. This will be rationally anticipated by $S$ when choosing c. Our results do, however, not hinge on this additional channel. To show this, we analyze in Section 4 also the case where for each buyer $c_{\text {Out }}^{i}$ is exogenously given. ${ }^{16}$

\subsection{Negotiations}

For the second stage of the model, where supply contracts are determined, we use the following simple bargaining model. Bargaining proceeds in pairwise negotiations, where $S$ is represented by $I$ different agents, each negotiating with one buyer. The agents of $S$ form rational expectations about the outcome in all other pairwise negotiations, while their objective is to maximize $S$ 's payoff. ${ }^{17}$ Our approach to the individual pairwise negotiations is axiomatic, though we provide a non-cooperative foundation in Appendix B. We employ the axiomatic Nash bargaining solution.

We need not write down the Nash solution in its generality. Several features of our model ensure that the solution has a very simple characterization. Note first that as contracts can contain some fixed fee $\tau^{i}$ (and as both parties are risk neutral), the issue of maximizing (joint) surplus in each bilateral negotiation and that of how to share the surplus are no longer interwined. Take now one of the $I$ bilateral negotiations. We ask first which choice of the linear component $w^{i}$ ensures that the joint profits of $B^{i}$ and that of $S$ are maximized, taking the outcome of all other negotiations as given. As firms compete in quantities in each of the $N$ markets and as contracts are not observable, the choice of $w^{i}$ does not affect the payoff $S$ receives from all other buyers but $i$. Therefore, if a (strictly) beneficial agreement between $B^{i}$ and $S$ is feasible, it is uniquely optimal to set $w^{i}=c$.

Lemma 1. The requirement that joint surplus is maximized in each bilateral negotiation implies that $w^{i}=c$.

\footnotetext{
${ }^{16}$ That is, we will then conduct the simpler analysis of how a change in $c_{\text {Out }}^{i}$ for a given buyer affects the supplier's incentives. In contrast, our main analysis asks how incentives are affected by a change in buyers' size, which in turn affects all $c_{\text {Out }}^{i}$.

${ }^{17}$ Importantly, in the characterized unique equilibrium it will not be optimal for $S$ to "orchestrate" a multilateral deviation by all of its agents (see also further below). We choose this set-up, where $S$ is represented by $I$ agents, as we also make use of it in the non-cooperative foundation that we provide in Appendix B.
} 
Lemma 1 is a restatement of a well-known result. The supplier $S$ faces a problem of opportunism when dealing with multiple buyers. Optimally, $S$ would like to commit to only supply one firm (that is, to the respective buyer) in each of the $N$ markets, which would allow to generate monopoly profits. ${ }^{18}$ This problem has been analyzed, though with different focus, in a number of papers, including Hart and Tirole (1990), McAfee and Schwartz (1994), or O'Brien and Shaffer (1994).

There is, however, one difference. In these papers, the supplier typically makes simultaneous offers to all downstream firms. ${ }^{19}$ Consequently, when observing its own offer, a given downstream firm must form beliefs on the (non-observable) offers made to all other competing downstream firms. The freedom to specify out-of-equilibrium beliefs generates multiple equilibria. In these models, the outcome with $w^{i}=c$ is obtained under "passive beliefs", where downstream firms believe that the supplier does not adjust other offers when proposing them an unanticipated contract. Our specification that $S$ negotiates simultaneously through $I$ agents has the same implication.

By Lemma 1, the payoff of $S$ is just the sum of all fixed transfers $\tau^{i}$ that are made by buyers with which $S$ negotiated successfully. This implies, in particular, that the payoff that $S$ realizes with all other buyers is unaffected by an individual disagreement. ${ }^{20}$ Consequently, if all other negotiations are successful, the additional surplus that is generated by an agreement between $S$ and $B^{i}$, that controls $n^{i}$ firms, is simply

$$
n^{i}\left[R\left(q_{S}, q_{S}\right)-q_{S} c\right]
$$

How is this shared between the two parties? Suppose first $B^{i}$ has no valuable alternative source of supply, e.g., as the involved fixed costs $F$ are sufficiently high. The asymmetric Nash solution allows for an arbitrary sharing rule, according to which, say, $B^{i}$ receives the fraction $0 \leq \rho^{i} \leq 1$ of (1). As discussed in the Introduction, several papers have suggested to model

\footnotetext{
${ }^{18}$ There are many possible contracts that would allow for such a commitment, e.g., to grant one firm exclusivity in the respective market. Our analysis, as well as that of related papers in the literature, cover markets where such contracts are not feasible as they would, for instance, constitute a non-permissible vertical restraint.

${ }^{19}$ A notable exception is O'Brien and Shaffer (1994), who also adopt an axiomatic Nash bargaining approach.

${ }^{20}$ The chosen axiomatic setting, whereby bilateral contracts are pinned down by the symmetric Nash solution, does not allow to incorporate potential renegotiations following disagreement with some buyers. Importantly, however, following disagreement with some buyer $B^{i}$ there would be no scope for mutually beneficial renegotiations with all other buyers. This is an immediate consequence of Lemma 1, by which all bilateral contracts specify $w^{i}=c$.
} 
a change in buyer power by adjusting $\rho^{i}$. The shortcoming of this approach is that there is no theory to support this. Non-cooperative models of bargaining - as the one we present in Appendix B - allow to endogenize $\rho^{i}$ from assumptions on how impatient the two parties are to come to an agreement. We know of no theory that would suggest how a buyer's size should affect its discount factor. Being agnostic about the sharing rules $\rho^{i}$, we simply set all $\rho^{i}$ equal to $1 / 2 .^{21}$

Suppose next that $B^{i}$ has a valuable alternative supply option following disagreement with $S$. As noted previously, the option to integrate backwards is only taken up after disagreement was reached. Hence, if this option is less valuable than $1 / 2$ of (1), the threat to integrate backwards is not credible. This is the key insight of what has been termed the "outside option principle." 22 The outside option is only relevant if its value exceeds the payoff that the buyer could realize when negotiating without such an option, i.e., in our case $1 / 2$ of (1). If the outside option becomes relevant as it exceeds this value, i.e., 1/2 of (1), then the outside option fully pins down the outcome of the negotiation in that it determines the buyer's profits. ${ }^{23}$

The value of the outside option of $B^{i}$, which we denote by $V_{O u t}^{i}$, is now easily derived as follows. If $B^{i}$ chooses to integrate backwards, it can still decide on the amount $K_{B}\left(\Delta_{B}^{i}\right)$ it wants to invest in order to reduce marginal costs to $c_{\text {Out }}^{i}=\bar{c}_{O u t}-\Delta_{B}^{i}$. Given $c_{\text {Out }}^{i}$, $B^{i}$ has then to decide what quantities it wants to supply to all of its $n_{i}$ firms. Recall that by Lemma 1 all of its competitors in the $n_{i}$ markets choose the same quantity $q_{S}$. Taken together, if $B^{i}$ decides to integrate backwards so as to still be active, its payoff equals

$$
v_{\text {Out }}^{i}:=\max _{\Delta_{B}^{i}}\left\{n^{i} \max _{q}\left[R\left(q, q_{S}\right)-\left(\bar{c}_{\text {Out }}-\Delta_{B}^{i}\right) q\right]-K_{B}\left(\Delta_{B}^{i}\right)-F\right\} .
$$

As there is always the option not to be active any longer, the outside option of $B^{i}$ is thus

\footnotetext{
${ }^{21}$ While this makes all expressions simpler, none of our qualitative results depends on the particular choice, that is as long as $0<\rho^{i}<1$ for all $B^{i}$. However, as we latter consider the formation of larger buyers through mergers, it would then fall upon us to specify which value of $\rho$ (or, in the non-cooperative model of Appendix B, which discount factor) to apply to the merged buyer. Again, there is no theory that could guide our choice.

${ }^{22}$ See the referenced seminal papers in Footnote 5 of the Introduction.

${ }^{23}$ Binmore, Rubinstein, and Wolinksy (1989) derive this from a non-cooperative model with alternating offers and impatient players. (See also Appendix B for a related model.) They also show that the outcome would differ if one assumed, as it is also sometimes the case in the bargaining literature, that frictions arise due to some exogenous probability by which negotiations break down if there is delay. (The "typical" story is that players negotiate on the phone and that the telephone line may get irrevocably interrupted.) This alternative scenario seems not very suitable to describe a setting of inter-firm bargaining with professional negotiators and potentially non-negligible sums at stake.
} 
equal to $V_{\text {Out }}^{i}=\max \left\{0, v_{\text {Out }}^{i}\right\}$. The following assumption now ensures that there will always be a mutually beneficial agreement between $S$ and all $B^{i} .{ }^{24}$

Assumption 2. For all $c \leq \bar{c}$ (and thus for all feasible $q_{S}$ ) and for all $n_{i} \leq N$, it holds that $V_{\text {Out }}^{i}<n^{i}\left[R\left(q_{S}, q_{S}\right)-q_{S} c\right]$.

We have thus arrived at the following set of results.

Proposition 1. Under Assumption 2 and the symmetric Nash bargaining solution, there is an agreement in all bilateral negotiations, where $w^{i}=c$ and where $\tau^{i}$ satisfies the following requirements. If

$$
\frac{1}{2} n^{i}\left[R\left(q_{S}, q_{S}\right)-q_{S} c\right] \geq V_{\text {Out }}^{i}
$$

then $\tau^{i}$ satisfies

$$
\tau^{i}=\frac{1}{2} n^{i}\left[R\left(q_{S}, q_{S}\right)-q_{S} c\right]
$$

Otherwise, we have that

$$
\tau^{i}=n^{i}\left[R\left(q_{S}, q_{S}\right)-q_{S} c\right]-V_{\text {Out }}^{i}
$$

In what follows, we refer to the case where (3) does not hold, i.e., where $\tau^{i}$ is determined by (5), as the case where the outside option of $B^{i}$ binds.

Note finally that the chosen bargaining solution allows $S$ to discriminate between different buyers. In the present setting the cause for this discrimination are buyers' different outside options, which in turn derive from buyers' different size.

\section{Analysis of the Supplier's Incentives}

This is the core analysis of our paper. We are interested in how the formation of larger buyers affects the incentives of supplier $S$ to reduce its costs of production in the first stage of the model. As a first step, we ask how the outcome of negotiations change if there are fewer but larger buyers with which $S$ has to negotiate.

\footnotetext{
${ }^{24}$ Assumption 2 is stronger than needed as it will have to hold only under the equilibrium choices of $c$. Invoking the stronger assumption allows, however, to rule out case distinctions when deriving our results.
} 
Suppose first that regardless of $n^{i} \leq N$ and given some choice of $c,(3)$ always holds such that the outside option does not bind for any buyer. For instance, the fixed costs $F$ could be very large such that $V_{\text {Out }}^{i}=0$ for all $B^{i}$ and $n^{i}$. For a given buyer $B^{i}$, the total surplus (1) as well as $\tau^{i}$ as given by (4) then both increase linearly in the size $n^{i}$. Consequently, the average price that $B^{i}$ pays per unit, which is equal to

$$
\mu^{i}:=\frac{\tau^{i}+n^{i} q_{S} c}{n^{i} q_{S}},
$$

is then $\left[c+P\left(2 q_{S}\right)\right] / 2$ and thus independent of the buyer's size $n^{i}$. Irrespective of the number and size of buyers, $S$ realizes the profits $N\left[R\left(q_{S}, q_{S}\right)-q_{S} c\right]$, which are taken gross of the initial investment outlay $K_{S}$. (Note that we use that there are altogether two times $N$ firms as two firms are active in each of the $N$ independent markets.)

The number and size of buyers start to matter, however, if buyers' outside options become binding. With a binding outside option, the average price (6) that $B^{i}$ pays will be strictly decreasing in $n^{i}$. The intuition for this is as follows. Integrating backwards involves two types of fixed up-front costs: $F$ and the additional investment $\operatorname{costs} K_{B}\left(\Delta_{B}^{i}\right)$, which depend on the (optimally) chosen level of cost reduction $\Delta_{B}^{i}$. The larger $n^{i}$, the larger the total quantity over which the buyer can distribute these costs. As a consequence, the ratio $V_{\text {Out }}^{i} / n^{i}=v_{\text {Out }}^{i} / n^{i}$ is strictly increasing in $n^{i}$. By Proposition 1, the negotiated fixed transfer $\tau^{i}$ then increases less than proportionally with $n^{i}$, implying finally that the per-unit purchasing price $\mu^{i}$ as defined in (6) strictly decreases with $n^{i}$.

In addition, the larger $n^{i}$ the more profitable it becomes for $B^{i}$ to actually integrate backwards and to invest more in reducing per-unit cost. Consequently, if $B^{i}$ chooses to integrate backwards, then it will compete at lower marginal $\operatorname{costs} c_{\text {Out }}^{i}$ the larger the size $n^{i}$.

Lemma 2. Holding the supplier's marginal cost c constant, a given buyer's size $n^{i}$ has the following impact on the buyer's outside option $V_{\text {Out }}^{i}$ and thereby on the respective bargaining outcome.

i) If after disagreement the buyer weakly prefers to integrate backwards for some $n^{i}=n^{\prime}$, then the buyer strongly prefers to do so for all $n^{i}=n^{\prime \prime}>n^{\prime}$. Moreover, in case of backward integration the buyer with size $n^{i}=n^{\prime \prime}$ invests strictly more so as to reduce $c_{\text {Out }}^{i}$ than if $n^{i}=n^{\prime}$. 
ii) Unless the outside option never binds regardless of the choice of $n^{i} \leq N$, there exists a threshold $1 \leq \widehat{n} \leq N$ such that for all $n<\widehat{n}$ the outside option of $B^{i}$ is not binding, while it is binding for all $n \geq \widehat{n}$. Over all $n^{i}=n<\widehat{n}$ the average price per unit, $\mu^{i}$, remains constant, while $\mu^{i}$ is strictly decreasing in $n^{i}$ over all $n^{i} \geq \widehat{n}$.

Proof. See Appendix.

It should be noted that the optimal level of $\Delta_{B}^{i}$ that is chosen after disagreement need not be unique. Assertion i) then applies to the respective sets such that all $\Delta_{B}^{i}$ that are optimal for $n^{i}=n^{\prime \prime}$ are strictly larger than any $\Delta_{B}^{i}$ that is optimal for $n^{i}=n^{\prime}$.

We turn now to the first stage of our model. Using Proposition 1, $S$ chooses its marginal $\operatorname{costs} c=\bar{c}-\Delta_{S}$ so as to maximize its total payoff

$$
U:=\sum_{i \in I} \tau^{i}-K_{S}\left(\Delta_{S}\right)
$$

where the transfers $\tau^{i}$ are determined by (4) and (5), respectively. It is now easily checked that $U$ is continuous and almost everywhere differentiable in $\Delta_{S} \cdot{ }^{25}$ To analyze the incentives of $S$, define thus the derivative $m:=d\left(U-K_{S}\left(\Delta_{S}\right)\right) / d \Delta_{S}$ at all points where $U$ is differentiable.

It seems intuitive that if it were not for the associated strictly positive investment costs $K_{S}$, the supplier would want to set marginal costs as low as possible. It is, however, well-known that the standard Cournot assumptions that we invoked in Assumption 1 are not sufficient to guarantee this. In what follows, we want to ensure that this intuitive property holds. We thus invoke the following additional assumption. ${ }^{26}$

Assumption 3. The per-firm Cournot profits $R\left(q_{S}, q_{S}\right)-c q_{S}$ are strictly decreasing in $c$.

If for a given choice of $c$ all buyers' outside options do not bind, the supplier's incentives to (marginally) decrease $c$ are given by

$$
m=N \frac{d}{d c}\left[R\left(q_{S}, q_{S}\right)-c q_{S}\right]-K_{S}^{\prime}\left(\Delta_{S}\right)
$$

\footnotetext{
${ }^{25}$ Formally, this follows from the definition of $U$ in $(7)$ and the definition of all $\tau_{S}^{i}$ in Proposition 1 , together with the smoothness of the Cournot game and the fact that all $v_{\text {Out }}^{i}$ are continuous and non-decreasing in $c$ and thus in $\Delta_{S}$.

${ }^{26}$ Vives (1999, p. 105) provides sufficient conditions on the demand function that ensure that Assumption 3 holds.
} 
where we used Proposition 1 and the fact that there are $2 N$ downstream firms. How do incentives change if instead the outside option of some buyer, say buyer $B^{i}$, binds? We can isolate three effects that all point in the same direction, that is towards an increase in the derivative $m$.

First, as the outcome of negotiations with $B^{i}$ is now fully pinned down by the buyer's outside option, $S$ can pocket the full marginal increase in the respective joint surplus $n^{i}\left[R\left(q_{S}, q_{S}\right)-c q_{S}\right]$ instead of only one half of it as in (8). That is, with a binding outside option there is no longer a hold-up problem between $S$ and $B^{i}$, at least not for marginal changes in the investment level and thus in $\Delta_{S} \cdot{ }^{27}$

Second, the supplier can reduce the outside option of $B^{i}$ and, thereby, increase the negotiated transfer $\tau^{i}$ by investing in a lower $c$. To see this, note that in each of the $n^{i}$ markets in which firms controlled by $B^{i}$ are active, $S$ will still supply the competing firms after disagreeing with $B^{i}$. The lower $c$, the more competitive are these firms, which reduces the value of the buyer's outside option to integrate backwards instead of being supplied by $S .{ }^{28}$ More formally, in contrast to the expression (8) where all buyers' outside options were non-binding, for each $B^{i}$ whose outside option binds there is now an additional positive term that captures the negative impact of a reduction of $c$ on $V_{\text {Out }}^{i}$. (See the proof of Lemma 3 for details.)

Finally, we find that the latter effect is also stronger the larger the buyer $B^{i}$. The intuition for this is as follows. Recall first from Lemma 2 that a larger buyer will optimally choose a lower value of $c_{\text {Out }}^{i}$ after disagreement, which in turn makes it optimal to choose a larger quantity in each of the $n^{i}$ markets where the buyer's firms are active. If competing firms also choose a large quantity, which will be the case if the supplier's marginal costs $c$ are also low, this reduces the price that $B^{i}$ can obtain per unit and will thus hurt $B^{i}$ more the larger its output per market.

Note that for the preceding arguments we scaled up the size of one buyer, $B^{i}$. If all other buyers' size was kept fixed, we would not only change the size of one buyer but also the scale of the whole market. To keep the market size constant, we thus suppose now that a larger buyer is formed through the merger of two or more buyers, which keeps the number of independent

\footnotetext{
${ }^{27}$ Recall our convention by which the outside option of $B^{i}$ is binding if (3) does not hold. Consequently, as $R\left(q_{S}, q_{S}\right)-c q_{S}$ and $v_{\text {Out }}^{i}$ both change continuously in $c$, the outside option of $B^{i}$ stays binding after a small change in $\Delta_{S}$.

${ }^{28}$ Formally, with quantity competition and given Lemma 1, a lower $c$ will translate into a higher quantity $q_{S}$ of all firms that compete with $B^{i}$.
} 
markets $N$ constant while reducing the number of buyers. ${ }^{29}$

Lemma 3. Consider for some fixed value $\Delta_{S}$ the marginal incentives for the supplier to increase $\Delta_{S}$, as given by the derivative $m$ (where it exists). If following a merger of buyers the outside option of the merged firm binds, then $m$ is strictly higher after the merger. Otherwise, $m$ does not change.

Proof. See Appendix.

With Lemma 3 at hands, it is now straightforward to prove our main result, namely that the exercise of buyer power leads to higher investment incentives for $S$ and thus lower production costs and higher output. ${ }^{30}$

Recall first that the supplier's payoff is continuous in $\Delta_{S}$. Where it is also differentiable both before and after the merger, we know from Lemma 3 that the derivative $m$ is not lower after the merger, while it is strictly higher in case the merged buyer's outside option binds at this choice of $\Delta_{S}$. The arguments in Lemma 3 now apply in the same way to values $\Delta_{S}$ where the supplier's payoff is not differentiable either before or after the merger, though now the assertions relate to the respective left-side and the right-side derivatives. ${ }^{31}$ From standard comparative statics results (see Milgrom and Roberts (1990) or Vives (1999)) we then have the following results.

Proposition 2. If there are fewer and larger buyers, then the supplier's optimal choice of $\Delta_{S}$ is never lower, but it can be strictly higher.

Proposition 2 is our key result. It asserts that the creation and exercise of buyer power will not lead to lower investment by the supplier, but may instead increase investment, and thereby,

\footnotetext{
${ }^{29}$ Recall that we assume throughout our analysis that no buyer $i \in I$ controls more than one of the two firms competing in any of the $N$ (sub-)markets. We thereby rule out monopolization effects, which would arise if buyers with competing firms merged. Besides allowing us to focus purely on buyer power originating from buyers' size, it is also reasonable that following a merger antitrust authorities require buyers to divest firms in markets where the merger would otherwise lead to a (local) monopoly.

${ }^{30}$ It should be noted that our comparative analysis is across different structures of the downstream market. That is, if we apply the picture of a merger to form a larger buyer, then the merger precedes the investment of $\Delta_{S}$.

${ }^{31}$ The respective left- and right-side derivatives always exist. There are two reasons for why there can be a "kink". First, there is a kink at all $\Delta_{S}$ where (3) is satisfied with equality for some $B^{i}$, either before or after the merger. Second, there is a kink at all $\Delta_{S}$ and corresponding $q_{S}$ where for some buyer $B^{i}$ the set of optimal choices for $\Delta_{B}^{i}$ following disagreement is not singular.
} 
lead to lower marginal costs. ${ }^{32}$

An application of Proposition 2 could be to retailing, where a larger buyer is formed by the merger of two or more smaller retail chains. In retailing, markets are often locally segmented such that the merger of chains operating in different regions may indeed have no implications for downstream competition. Likewise, structural remedies are easily applicable by forcing merging chains to divest outlets in local markets where their merger would seriously reduce the number of competitors. When dealing with large chains, there is essentially no longer any scope for negotiations: Average purchasing costs $\mu^{i}$ are pinned down by the chains' more attractive alternative supply options. Lemma 3 and Proposition 2 show how this can spur upstream investment to reduce marginal costs.

Proposition 2 is silent about the overall welfare effects. It is straightforward that $S$ invests too little in the reduction of marginal costs if all outside options are non-binding. Intuitively, as there is a hold-up problem with respect to all buyers, $S$ chooses a level of $\Delta_{S}$ that is below the level that would maximize total industry profits. But the level of $\Delta_{S}$ that would maximize total industry profits is already too low from a welfare perspective: a further reduction of marginal costs $c$ would lead to lower output and, thereby, a lower deadweight loss. In the opposite extreme where all outside options are binding, $S$ pockets the total incremental industry profits that are generated by a marginal reduction of $c$. Additionally, $S$ has an incentive to reduce costs even further as this reduces the value of buyers' outside options. If the latter effect is not too strong, the formation of larger buyers increases welfare, even if it may reduce total industry profits. However, there is no guarantee that $S$ will not "overshoot" by choosing too low costs in the presence of large buyers.

Finally, we want to analyze how the formation of larger buyers affects other buyers in the industry. With two-part tariffs, the increased buyer power of large buyers has no direct impact on the linear component $w_{\text {Out }}^{i}$, which determines how competitive buyers are in the different markets. (Recall that $w_{\text {Out }}^{i}=c$ holds for all buyers.) Consequently, other buyers are affected by a merger only through its impact on the supplier's incentives. This observation yields now a somewhat surprising result. Small buyers that do not have a valuable outside option benefit

\footnotetext{
${ }^{32}$ Lemma 3 already pointed to one possibility why the result may not hold strictly and a merger may thus not affect the set of optimal values, namely that the outside option does not bind over the relevant range of $\Delta_{S}$ even for the (larger) merged buyer. Another possibility is that without the merger there is a single optimal choice of $\Delta_{S}$ and that $U$ has a kink at this value $\Delta_{S}$.
} 
from the merger as they can extract a fraction of the additional joint profits that are generated by the supplier's lower costs. In contrast, large buyers may be hurt as this decreases the value of their respective (binding) outside options.

Corollary 1. Suppose a merger changes the supplier's investment choice. Then the payoff of buyers that are outside the merger is affected as follows. If a buyer is sufficiently small such that before the merger its outside option is not binding, then its payoff strictly increases. If a buyer is sufficiently large such that after the merger its outside option is binding, then its payoff strictly decreases.

Proof. See Appendix.

We conclude this section with an illustration.

\section{Example}

Suppose inverse demand is linear with $P(q)=a-b q$, for $q \leq a / b$ with $a, b>0$. Furthermore, the market structure is such that there are $2 k$ symmetric buyers, each controlling $n^{i}=\bar{n}:=N / k$ firms. In other words, we can "line up" the buyers such that of the first set of $k$ buyers each controls the "first" firm in one of the $N$ independent market, while each of the "second" firms is controlled by one of the second set of $k$ buyers. We restrict attention to values of $k$ and $N$ where $\bar{n}$ is an integer. For instance, for $k=1$ we have $I=2$ buyers, each controlling one firm in the $N$ markets and thus altogether $\bar{n}=N$ firms. At the other extreme, we have for $k=N$ that each buyer only controls one firm $(\bar{n}=1)$.

We consider the quadratic investment technologies $K_{S}\left(\Delta_{S}\right)=\frac{1}{2} \gamma_{S}\left(\Delta_{S}\right)^{2}$ and $K_{B}\left(\Delta_{B}^{i}\right)=$ $\frac{1}{2} \gamma_{B}\left(\Delta_{B}^{i}\right)^{2}$, with $\gamma_{S}, \gamma_{B}>0$. Recall now that we assumed so far that the derivative of $K_{S}$ goes to infinity as $\Delta_{S} \rightarrow \bar{c}$ and that the derivative of $K_{B}$ goes to infinity as $\Delta_{B}^{i} \rightarrow \bar{c}_{\text {Out }}$. This allowed to rule out one type of corner solutions in the investment decisions, which in turn allowed to streamline the exhibition of results. The quadratic investment technologies no longer exhibit this property. As shown in Appendix C, a sufficient assumption to rule out corner solutions is that $N<b \min \left\{\gamma_{B}, \gamma_{S}\right\}$ and that $\bar{c}=\bar{c}_{O u t}=a / 2$. We further set $F=0$.

Note next that as buyers are symmetric, the outside option binds either for all or for none. As we show in Appendix $\mathrm{C}$, we then have for a given size $\bar{n} \leq N$ that the buyers' outside option 
binds if $\Delta_{S}$ is not too large, satisfying

$$
\Delta_{S}<\widehat{\Delta}_{S}:=\frac{a}{2} \frac{\bar{n}-4 b \gamma_{B}+3 \sqrt{b \gamma_{B}\left(2 b \gamma_{B}-\bar{n}\right)}}{b \gamma_{B}-\bar{n}} .
$$

It can be shown that $\widehat{\Delta}_{S}$ is strictly increasing in $\bar{n}$, i.e., the range of the supplier's costs for which the buyers' outside option is binding increases with buyers' size. In Appendix C we also show that the supplier's payoff $U$ is strictly concave both over $\Delta_{S} \geq \widehat{\Delta}_{S}$, where the outside option does not bind, and over $\Delta_{S}<\widehat{\Delta}_{S}$, where the outside option binds. This ensures that there are only three possible solution candidates for the supplier's problem, namely choosing $\Delta_{S}$ to satisfy the first-order condition over either the range where the outside option binds or the range where it does not bind, or choosing $\Delta_{S}$ so that $\Delta_{S}=\widehat{\Delta}_{S}$, where $U$ has a kink.

In the following numerical example the last case applies. Figure 1 gives $U$ as a function of the supplier's cost reduction $\Delta_{S} \in[0, a / 2]$, where we further specified that $a=1, b=9$, $\gamma_{S}=\gamma_{B}=10$, and $N=80$. One graph gives $U$ for the extreme case where $\bar{n}=1$ and one graph gives $U$ for the opposite extreme where $\bar{n}=N=80$. The two graphs are identical over high values of $\Delta_{S}$, where the outside option does not bind in either scenario. For all lower values of $\Delta_{S}$, where the outside option binds if there are fewer but larger buyers, $U$ is strictly lower in case $\bar{n}=80$. The optimal values for $\Delta_{S}$ are at the two respective kinks, with the value for $\bar{n}=80$ being strictly higher than that for $\bar{n}=1 .{ }^{33}$

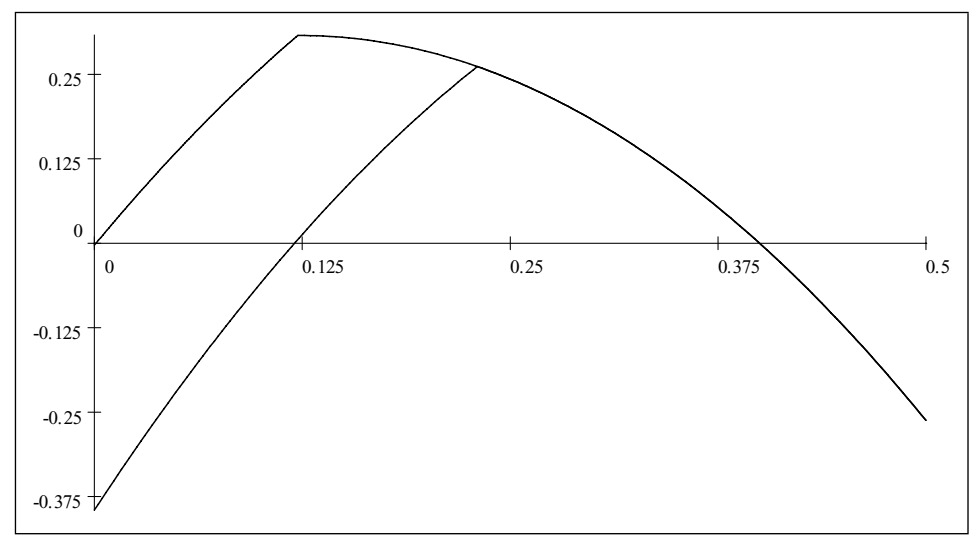

Figure 1

\footnotetext{
${ }^{33}$ While the picture brings out clearly that the derivative w.r.t. $\Delta_{S}$ is higher for $\bar{n}=80$ over the range where the outside option binds for $\bar{n}=80$ but not for $\bar{n}=1$, the small difference in the respective values makes it hard to see in the picture that this is also the case for all lower values of $\Delta_{S}$ where the outside option binds in both cases.
} 


\section{Discussion}

\subsection{Exogenous Outside Options}

In our setting, buyers have to invest in their outside option after disagreement with $S$. The resulting marginal costs $c_{\text {Out }}^{i}$, at which a given $B^{i}$ can compete in its $n^{i}$ markets after disagreement, are thus determined endogenously. As a consequence, the supplier's choice of $c$ also affects a buyer's own investment to reduce costs after disagreement, $\Delta_{B}^{i}$, which is in turn anticipated by the supplier when choosing $\Delta_{S}$ in the first stage.

In what follows, we show that our main results still hold even if buyers' outside options are exogenously given. That is, we now assume that each buyer $B^{i}$ has a fixed alternative supply option, which is associated with some fixed $\operatorname{costs} F$ and marginal $\operatorname{costs} c_{\text {Out }}^{i}$. The differences in $c_{\text {Out }}^{i}$ across buyers may not necessarily be linked to size. The antitrust literature knows the concept of "buyer sophistication", according to which some buyers are classified as being better at extracting discounts from suppliers. ${ }^{34}$ We find that as we (exogenously) reduce $c_{\text {Out }}^{i}$ for one or more buyers, thereby making their outside options more attractive, we obtain the same results as in Proposition 2, where we changed buyer size.

Proposition 3. Suppose that the outside option of each buyer $B^{i}$ is characterized by some exogenously given value $c_{\text {Out }}^{i}$. Then lowering $c_{\text {Out }}^{i}$ for one or more buyers has the same implications for the supplier's optimal choice of $\Delta_{S}$ as the formation of a larger buyer in Proposition 2.

Proof. See Appendix.

\subsection{Outside vs. Inside Options}

Our analysis captured buyer power via the attractiveness of a buyer's option to permanently switch away from the given supplier $S$, which was in turn a function of the buyer's size. Importantly, it is only after breaking up negotiations with $S$ that the buyer would build up its own supply capacity (or, alternatively, that the buyer would spend resources to locate and switch

\footnotetext{
${ }^{34}$ See Steptoe (1993) and Nordemann (1995). A buyer could be more "sophisticated" as its longer history in the business gives it (or, better, its staff) a better picture of the alternative supply options. Also, a buyer may be better equipped to either integrate backwards or locate a suitable substitute if it produces technically similar components.
} 
to another supplier). Walking away from the negotiations with $S$ is only optimal if the buyer can not expect more from an agreement with $S$ than from its alternative supply option. The key consequences of these observations were that for small buyers the value of their alternative supply option is inconsequential for the outcome of negotiations, while for large buyers their payoff from the negotiations is determined by their "binding outside option".

The bargaining literature makes a distinction between such "outside options", which are triggered by permanent disagreement, and so-called "inside options", which provide value to the respective party while negotiating. Applied to our setting, a buyer's inside option would thus consist of the possibility to temporarily purchase a substitute for the input of $S$.

We formally introduce such an inside option in the non-cooperative model of Appendix B. Though this will not be the case in equilibrium, two parties could continue haggling with offers and counteroffers over a number of rounds. It is during this time, precisely over each time interval between a rejected offer and a counteroffer, that the respective buyer can draw on its inside option. Given this short time span, it seems reasonable to suppose the such an inside option could at best be some readily available, though possibly inferior or due to distance or other constraints more expensive, source of supply. For instance, any buyer - that is, regardless of its size - may be able to purchase a less suitable input at the world market.

In Appendix B we show that incorporating an inside option in this way into a non-cooperative bargaining model yields the same solution as the axiomatic Nash solution once we make the following adjustments. Buyers now have also the inside option of purchasing the input at some common costs $c_{I n} .{ }^{35}$ To ensure again that there is always a mutually beneficial agreement with $S$, we assume that $c_{I n}>\bar{c}$. When purchasing from this source of supply, buyer $B^{i}$ would realize the payoff $f^{36}$

$$
V_{I n}^{i}:=n^{i} \max _{q}\left[R\left(q, q_{S}\right)-q c_{I n}\right] .
$$

Suppose now for a moment that the outside option of $B^{i}$ does not bind, e.g., as $V_{\text {Out }}^{i}=0$ given that $F$ is sufficiently large. In this case, we can incorporate the inside option into the Nash bargaining solution as follows. $B^{i}$ realizes now the value of its inside option, $V_{I n}^{i}$, plus one

\footnotetext{
${ }^{35}$ Note that if the input from this source was less suitable to buyers' needs, then this could be captured by increasing $c_{I n}$ to take into account any additional adjustment costs.

${ }^{36}$ In Appendix B we show that even though a buyer would only temporarily use the inside option, i.e., as long as there is delay, what matters for the bargaining outcome is the discounted value that the buyer would generate by indefinitely drawing instead on this source of supply. Note also that $V_{I n}^{i} \geq 0$.
} 
half of the incremental surplus from an agreement with $S$, which is now equal to the respective incremental profits $n^{i}\left[R\left(q_{S}, q_{S}\right)-c q_{S}\right]$ minus the buyer's inside option $V_{I n}^{i}$. The payoff of $B^{i}$ is then

$$
\begin{aligned}
& V_{I n}^{i}+n^{i} \frac{1}{2}\left[n^{i}\left[R\left(q_{S}, q_{S}\right)-c q_{S}\right]-V_{I n}^{i}\right] \\
= & \frac{1}{2}\left[n^{i}\left[R\left(q_{S}, q_{S}\right)-c q_{S}\right]+V_{I n}^{i}\right] .
\end{aligned}
$$

The key difference between the inside and the outside option is that the latter becomes only relevant after disagreement. Instead, the buyer uses the inside option during negotiations. Consequently, the surplus that is up for negotiations between $B^{i}$ and $S$ is reduced by $V_{I n}^{i}$ - and it is again shared equally, provided that the outside option does not bind. If the outside option of $B^{i}$ binds, the buyer realizes again $V_{O u t}^{i}$ irrespective of $V_{I n}^{i} \cdot{ }^{37}$

Proposition 4. Suppose that buyers have in addition the "inside option" to purchase at costs $c_{I n}>c$. Then under the symmetric Nash bargaining solution there is an agreement in all bilateral negotiations, where $w^{i}=c$ and where $\tau^{i}$ satisfies the following requirements. If

$$
\frac{1}{2}\left[n^{i}\left[R\left(q_{S}, q_{S}\right)-c q_{S}\right]+V_{I n}^{i}\right] \geq V_{\text {Out }}^{i},
$$

then $\tau^{i}$ satisfies

$$
\tau^{i}=\frac{1}{2} n^{i}\left[R\left(q_{S}, q_{S}\right)-q_{S} c\right]-\frac{1}{2} V_{I n}^{i}
$$

Otherwise, we have that

$$
\tau^{i}=n^{i}\left[R\left(q_{S}, q_{S}\right)-q_{S} c\right]-V_{O u t}^{i}
$$

Note first that holding $c_{I n}$ constant, the introduction of an inside option does not change our results qualitatively. That is, all results on the impact of buyer size on incentives extend once we use Proposition 4 instead of Proposition 1 to characterize the bargaining solution.

In addition, Proposition 4 allows us to investigate how a change in the inside option affects the outcome of negotiations and thereby the supplier's incentives. The lower $c_{I n}$, the more valuable becomes the buyers' inside option. Unless the outside option of all buyers is binding

\footnotetext{
${ }^{37}$ Note that Proposition 4 uses the assumption that the buyer's outside option is more attractive than its inside option, $V_{\text {Out }}^{i} \geq V_{I n}^{i}$. If this was not the case, the buyer would continue to draw on the inside option after breaking up with $S$ such that $V_{O u t}^{i}=V_{I n}^{i}$. In this case, the outside option would, however, never bind.
} 
also after the decrease in $c_{I n}$, in which case the outcome of negotiations is not affected, a lower $c_{I n}$ thus reduces the supplier's payoff.

To study the implications on the supplier's incentives, take some $B^{i}$ and consider a reduction in $c_{I n}$. If the outside option of $B^{i}$ binds with the lower $c_{I n}$, it also binds with the higher $c_{I n}$. Consequently, in this case negotiations between $S$ and $B^{i}$ are not affected by the change in the inside option. Suppose next that the outside option binds neither before nor after the change in $c_{I n}$ such that the respective transfers $\tau^{i}$ are determined by (12).$^{38}$ In this case, the supplier's incentives to lower $c$ come from two sources: $S$ obtains one half of the respective incremental profits and, in addition, one half of any reduction in $V_{I n}^{i}$. (That $V_{I n}^{i}$ decreases in $\Delta_{S}$ follows from the same arguments why $v_{\text {Out }}^{i}$ decreases in $\Delta_{S}$.) By applying the arguments from Lemma 3 we can again show that the latter effect is stronger the more attractive the inside option, i.e., the higher $V_{I n}^{i}$ and thus the lower $c_{I n}$. The final case is that were the outside option of $B^{i}$ binds before but not after a reduction in $c_{I n}$. As the (marginal) incentives of the supplier are higher if the outside option binds, incentives are reduced in this case.

From these observations it is clear that a reduction of $c_{I n}$ can both increase or decrease the supplier's incentives to reduce marginal costs. Proposition 5 isolates cases for which we can obtain unambiguous results.

Proposition 5. Suppose that buyers have in addition the "inside option" as characterized by $c_{\text {In }}$. If the inside option is made more attractive by lowering $c_{\text {In }}$, then the supplier's marginal incentives at some given $\Delta_{S}$ change as follows. If the outside option of all buyers does not bind before the change, then incentives are strictly higher in case $V_{I n}^{i}>0$ holds for some $B^{i}$ after the reduction in $c_{I n}$, while otherwise incentives are unchanged. If the outside option of all buyers binds before but not after the reduction in $c_{I n}$, then the supplier's incentives are strictly lower. If the outside option of all buyers binds after the change, then incentives are not affected.

Proof. See Appendix.

\footnotetext{
${ }^{38}$ For instance, this is the case if (11) holds strictly for $B^{i}$ and if we consider a sufficiently small adjustment in $c_{I n}$.
} 


\section{Conclusion}

We have provided a detailed analysis of how the presence of strong buyers can affect a supplier's investment incentives. We considered both the case where buyer power arises endogenously through size and the case where certain (say, "sophisticated") buyers are exogenously endowed with more attractive alternative supply options. We showed how the presence of more powerful buyers, e.g., the presence of fewer but larger buyers, makes it more profitable for the supplier to reduce marginal costs. This result stands in stark contrast to an often expressed view whereby the exercise of buyer power stifles suppliers' investment incentives. In a model with bilateral negotiations, a supplier can extract more of the incremental profits from reducing costs if it faces more powerful buyers, though the supplier's total profits decline. Furthermore, the presence of more powerful buyers creates additional incentives to lower marginal costs as this renders buyers' alternative supply options less valuable. The latter effect is due to downstream competition between buyers and, as we show, is also stronger the more powerful (e.g., larger) buyers already are.

Our analysis focuses on incentives to reduce marginal costs, which is also the subject of much of the literature that studies the impact of horizontal competition on firms' incentives. While we obtained what are arguably strong results for this particular case, we do not claim that our results apply more generally. For instance, a supplier could invest in product quality or in an advertising campaign aimed at increasing consumers' awareness of its product. Again, the presence of more powerful buyers may allow the supplier to extract more of the incremental profits generated from, say, an increase in product quality, while buyers' option to purchase a lower-quality good elsewhere may be much less profitable if other firms sell the supplier's superior product. We leave a formal analysis of such alternative investments to further work.

Finally, we endogenized buyer power from buyers' size, which in turn generated more valuable alternative supply opportunities. Depending on the particular industry, there may be, however, other sources of buyer power. For instance, customers' loyalty to particular retail shops may make it less likely that they will shop elsewhere if these shops drop a single brand. Alternatively, a retailer may be able to capture some of the revenues that are lost by delisting a supplier's good through selling more of (though possibly inferior) own-label products. It is an open question how buyer power that originates from these alternatives sources could affect suppliers' incentives. 


\section{Appendix A: Proofs}

Proof of Lemma 2. We study first the properties of $v_{\text {Out }}^{i}$. These properties will then immediately lead to assertion ii) and the first part of assertion i). To study the properties of $v_{\text {Out }}^{i}$, we denote the set of optimal choices for $\Delta_{B}^{i}$ by $D_{B}^{i}$. If following disagreement it is not optimal for $B^{i}$ to remain active, it is uniquely optimal to set $\Delta_{B}^{i}=0$ such that $v_{\text {Out }}^{i}=F / n^{i}$. Otherwise, we have from the properties of $K_{B}$ that all $\Delta_{B}^{i} \in D_{B}^{i}$ satisfy $\Delta_{B}^{i}>0$ and $0<\Delta_{B}^{i}<\bar{c}_{O u t}$ and given the smoothness of the Cournot game and differentiability of $K_{B}$ - that all $\Delta_{B}^{i} \in D_{B}^{i}$ are determined by the respective first-order conditions. Note next that we can treat $n^{i}$ as a continuos variable as all expressions in $v_{\text {Out }}^{i}$ are also defined over real values $n^{i}$. From the envelope theorem, $v_{\text {Out }}^{i}$ is then strictly increasing and strictly convex in $n^{i}$.

To complete the proof it remains to show that the set $D_{B}^{i}$ is strictly increasing in $n^{i}$, provided that $n^{i}$ is sufficiently large such that the buyer optimally chooses to be active after disagreement $\left(n^{i} \geq \widehat{n}\right)$. To see this, observe first that the cross-derivative of

$$
n^{i} \max _{q}\left[R\left(q, q_{S}\right)-q\left(\bar{c}_{O u t}-\Delta_{B}^{i}\right)\right]-K_{B}\left(\Delta_{B}^{i}\right)
$$

with respect to $\Delta_{B}^{i}$ and $n^{i}$ is strictly positive. The asserted property of $D^{i}$ follows then from standard comparative statics results (see Milgrom and Roberts (1990) or Vives (1999)). Q.E.D.

Proof of Lemma 3. Here and in what follows, we denote the set of the supplier's optimal choices for $\Delta_{S}$ by $D_{S}$. By our assumptions on the investment cost function $K_{S}$ and by Assumption 3, we have that $\Delta_{S}>0$ for all $\Delta_{S} \in D_{S}$. Denote next the set of merging buyers by $\widehat{I}$. Suppose that before the merger, the outside option was binding for buyers in the set $\widehat{I}^{\prime} \subseteq \widehat{I}$ and not binding for the buyers in the complementary set $\widehat{I} / \widehat{I}^{\prime}$. We denote the total number of firms controlled by the merged buyer by $\widehat{n}=\sum_{i \in \widehat{I}} n^{i}$. Note next that from Lemma 1 and Proposition 1 negotiations with all buyers $i \in I / \widehat{I}$ are not affected by the merger of buyers $i \in \widehat{I}$. Hence, to compare incentives we only have to compare the derivative of $\sum_{i \in \widehat{I}} \tau^{i}$ w.r.t. $\Delta_{S}$, which sums up the respective fixed transfers of the merging buyers, with the derivative of the single transfer that is subsequently paid by the merged buyer, which we denote by $\widehat{\tau}_{S}$ (in a slight abuse of notation). Likewise, we denote the merged buyer's outside option by $\widehat{v}_{\text {Out }}$.

We now distinguish between two cases. If the outside option is not binding for the merged buyer, then by Lemma 2 it is also not binding for all $i \in \widehat{I}$ before the merger. Consequently, we 
have from Proposition 1 that $^{39}$

$$
\frac{d}{d \Delta_{S}} \sum_{i \in \widehat{I}} \tau^{i}=\frac{d}{d \Delta_{S}} \widehat{\tau}_{S}=\frac{1}{2} \widehat{n} \frac{d}{d c}\left[R\left(q_{S}, q_{S}\right)-c q_{S}\right] .
$$

Suppose next that the merged buyer's outside option is binding. It is now helpful to introduce some additional notation for this case. For this purpose, take some buyer $B^{i}$. If this buyer's outside option is binding, then we have that $\Delta_{B}^{i}>0$ for all $\Delta_{B}^{i} \in D_{B}^{i}$. (Recall that $D_{B}^{i}$ denotes the set of optimal values $\Delta_{B}^{i}$ that are chosen by $B^{i}$ after disagreement with $S$.) From Assumption 1, we further have that for given $\Delta_{B}^{i}$ (and given $q_{S}$ ) there is a unique corresponding optimal quantity $q^{i}>0$ that $B^{i}$ chooses at all of its controlled $n^{i}$ firms. If the set $D_{B}^{i}$ is not singular, we denote the set of corresponding optimal choices of $q^{i}$ by $Q^{i}$. We already know from Lemma 2 that $D_{B}^{i}$ is strictly increasing in $n^{i}$ - that is, provided the buyer remains active after disagreement as $n^{i}$ is sufficiently large. As the cross-derivative of the buyer's disagreement payoff w.r.t. $\Delta_{B}^{i}$ and $q$ is strictly positive, we thus have that also $Q^{i}$ is strictly increasing in $n^{i}$. Next, $v_{\text {Out }}^{i}$ is continuous and non-increasing in $q_{S}$, implying that it is almost everywhere continuously differentiable. ${ }^{40}$ The derivative is $d v_{\text {Out }}^{i} / d q_{S}=n^{i} q^{i} P^{\prime}\left(q_{S}+q^{i}\right)$.

Proceeding likewise for the merged buyer, we denote (once more in a slight abuse of notation) the optimal levels of cost reduction after disagreement by $\widehat{\Delta}_{B} \in \widehat{D}_{B}$ and the corresponding optimal (per-firm) quantities by $\widehat{q} \in \widehat{Q}$. The resulting payoff for the merged buyer is now $\widehat{v}_{\text {Out }}$ with respective derivative $d \widehat{v}_{O u t} / d q_{S}=\widehat{n} \widehat{q} P^{\prime}\left(q_{S}+\widehat{q}\right)$.

Using these results and Proposition 1, we then have for the case where the merged buyer's outside option is binding that

$$
\frac{d}{d \Delta_{S}} \widehat{\tau}_{S}=\widehat{n} \frac{d}{d c}\left[R\left(q_{S}, q_{S}\right)-c q_{S}\right]-\frac{d \widehat{v}_{O u t}}{d q_{S}} \frac{d q_{S}}{d c}
$$

and

$$
\begin{aligned}
\frac{d}{d \Delta_{S}} \sum_{i \in \widehat{I}} \tau^{i}= & \sum_{i \in \widehat{I}^{\prime}}\left[n^{i} \frac{d}{d c}\left[R\left(q_{S}, q_{S}\right)-c q_{S}\right]-\frac{d v_{\text {Out }}^{i}}{d q_{S}} \frac{d q_{S}}{d c}\right] \\
& +\left(\sum_{i \in \widehat{I} / \widehat{I}^{\prime}} n^{i}\right) \frac{1}{2} \frac{d}{d c}\left[R\left(q_{S}, q_{S}\right)-c q_{S}\right] .
\end{aligned}
$$

\footnotetext{
${ }^{39}$ There is no need to write out the derivative in rectangular brackets, which is $q_{S}-\frac{d q_{S}}{d c} \frac{d}{d q_{S}}\left[\pi\left(q_{S}, q_{S}\right)-c q_{S}\right]$. Note that $q_{S}$ is continuously differentiable from our assumptions on the inverse demand $P$, while $d q_{S} / d c<0$.

${ }^{40}$ Precisely, $v_{\text {Out }}^{i}$ is continuously differentiable whenever $Q^{i}$ is singular.
} 
We want to show that (15) is strictly higher than (16). To see this, note first that by Assumption 3 we have that $d\left[R\left(q_{S}, q_{S}\right)-c q_{S}\right] / d c>0$. Next, observe that $d v_{O u t}^{i} / d q_{S}<0$ for all $i \in \widehat{I}$ and that also $d \widehat{v}_{O u t} / d q_{S}<0 .{ }^{41}$ We finally show that for all $i \in \widehat{I}$ it holds that

$$
\sum_{i \in \widehat{I}^{\prime}} \frac{d v_{\text {Out }}^{i}}{d q_{S}}>\frac{d \widehat{v}_{\text {Out }}}{d q_{S}},
$$

which in turn surely holds if we have for all $i \in \widehat{I}^{\prime}$ that

$$
q^{i} P^{\prime}\left(q_{S}+q^{i}\right)>\widehat{q} P^{\prime}\left(q_{S}+\widehat{q}\right)
$$

To see that (17) holds, note first that the expression $q P^{\prime}\left(q_{S}+q\right)<0$ is by Assumption 1 strictly decreasing in $q .{ }^{42}$ The assertion thus follows from our previous observation that $Q^{i}$ is strictly increasing in $n^{i}$. This completes the proof of Lemma 3. Q.E.D.

Proof of Corollary 1. We denote the supplier's optimal set of cost-reduction levels $\Delta_{S}$ before the merger by $D_{S}$ and the optimal set after the merger by $\widehat{D}_{S}$, where $\widehat{D}_{S}$ is higher than $D_{S}$ from Proposition 2. Suppose first that for $B^{i}$ the outside option does not bind for all $\Delta_{S} \in D_{S}$. As the joint surplus $R\left(q_{S}, q_{S}\right)-c q_{S}$ is strictly decreasing in $c$ and as $v_{\text {Out }}^{i}$ is non-increasing, it follows from (3) that the outside option is also not binding for all $\Delta_{S} \in \widehat{D}_{S}$ after the merger. Given that the payoff of $B^{i}$ is equal to $\left[R\left(q_{S}, q_{S}\right)-c q_{S}\right] / 2$ from (4), $B^{i}$ is by Assumption 3 strictly better off after the merger (and the resulting change in the supplier's marginal costs).

Take next some $B^{i}$ for which the outside option binds after the merger and for all respective optimal choices $\Delta_{S} \in \widehat{D}_{S}$ for the supplier in the first stage. By the same argument as before, the outside option of $B^{i}$ was then also binding before the merger and for all $\Delta_{S} \in D_{S}$. As $v_{O u t}^{i}$ is strictly lower the higher $\Delta_{S}, B^{i}$ is made strictly worse off by the merger (and the resulting change in the supplier's marginal costs). Q.E.D.

Proof of Proposition 3. In a slight abuse of notation, we adopt the same notation as in the previous game where $c_{\text {Out }}^{i}$ was endogenous. In particular, we have that

$$
v_{\text {Out }}^{i}=n_{i} \max _{q}\left[R\left(q, q_{S}\right)-q c_{\text {Out }}^{i}\right] .
$$

\footnotetext{
${ }^{41}$ It should be recalled that according to our definition the outside option is binding whenever (3) in Proposition 1 does not hold, implying from continuity that it remains binding also after a marginal adjustment of $c$ and thus of $q_{S}$.

${ }^{42}$ To be precise, note that differentiating $q P^{\prime}\left(q_{S}+q\right)$ w.r.t. $q$ gives $q P^{\prime \prime}\left(q_{S}+q\right)+P^{\prime}\left(q_{S}+q\right)$. By $P^{\prime}<0$ (wherever $P>0$ ) this is surely negative if also $P^{\prime \prime} \leq 0$. For the case where $P^{\prime \prime}>0$ note that by Assumption 1 we have $Q P^{\prime \prime}(Q)+P^{\prime}(Q)<0$, where $Q=q_{S}+q$, which is a weaker condition.
} 
Also, for given $q_{S}$, which in turn corresponds to a given $\Delta_{S}, B^{i}$ will choose a unique quantity $q^{i}$ maximizing (18). (Uniqueness follows from Assumption 1 and the fact that $c_{\text {Out }}^{i}$ is now exogenously given.) Also, whenever $q^{i}>0$ we have $d q^{i} / d c_{\text {Out }}^{i}<0$ and that

$$
\frac{d v_{O u t}^{i}}{d \Delta_{S}}=n^{i} \frac{d q_{S}}{d \Delta_{S}} q^{i} P^{\prime}\left(q_{S}+q^{i}\right)
$$

while $d v_{\text {Out }}^{i} / d c_{\text {Out }}^{i}<0$ whenever $q^{i}>0$. By $(19), d q^{i} / d c_{\text {Out }}^{i}<0$, and Assumption 1 we also have that $d v_{\text {Out }}^{i} / d \Delta_{S}$ is strictly lower the lower $c_{\text {Out }}^{i}$. With these two results, the arguments of Lemma 3 and Proposition 2 fully carry over. Q.E.D.

Proof of Proposition 5. Suppose first that the outside option for all $B^{i}$ does not bind before the reduction in $c_{I n}$. As $V_{O u}^{i}$ is unaffected by $c_{I n}$ while $V_{I n}^{i}$ is nondecreasing (and strictly increasing for all $V_{I n}^{i}>0$ ), we have from (11) that the outside option for all $B^{i}$ does also not bind after the reduction in $c_{I n}$. As all $\tau^{i}$ are then given by (12), we have both before and after the reduction of $c_{I n}$ that

$$
m=-N \frac{d\left[R\left(q_{S}, q_{S}\right)-q_{S} c\right]}{d c}-\frac{1}{2} \sum_{i \in I} \frac{d V_{I n}^{i}}{d \Delta_{S}}
$$

wherever $U$ is differentiable. Let now $q^{i}$ denote the by Assumption 1 unique optimal quantity choice of $B^{i}$ under the inside option of purchasing at $c_{I n}$. Then unless $q^{i}=0$ such that $d V_{I n}^{i} / d \Delta_{S}=0$, we have from (9) that

$$
\frac{d V_{I n}^{i}}{d \Delta_{S}}=n^{i} \frac{d q_{S}}{d \Delta_{S}} q^{i} P^{\prime}\left(q_{S}+q^{i}\right)
$$

Given (20) and (21), the rest of the argument is then identical to that in Lemma 3.

Suppose next that the outside option for all $B^{i}$ binds before but not after the reduction in $c_{I n}$. Consequently, after the reduction in $c_{I n}$ the marginal incentives $m$ are still given by (20), where we can substitute from (21). Before the reduction in $c_{I n}$, we have that

$$
m=-2 N \frac{d\left[R\left(q_{S}, q_{S}\right)-q_{S} c\right]}{d c}-\frac{1}{2} \sum_{i \in I} \frac{d V_{O u t}^{i}}{d \Delta_{S}}
$$

If we again denote the chosen quantity without being supplied by $S$ by $q^{i}$, though now under the respective optimal choice $c_{I n}$, we can substitute in (22) that

$$
\frac{d V_{O u t}^{i}}{d \Delta_{S}}=n^{i} \frac{d q_{S}}{d \Delta_{S}} q^{i} P^{\prime}\left(q_{S}+q^{i}\right)
$$


That (22) is then strictly larger than (20) follows again immediately from the arguments in Lemma 3. Precisely, we can use that $d\left[R\left(q_{S}, q_{S}\right)-q_{S} c\right] / d c<0$ by Assumption 3 and that $c_{\text {Out }}^{i}<c_{\text {In }}$, which from $F \geq 0$ and $K_{B} \geq 0$ follows strictly from the assumption that the outside option is binding and thus more attractive than the inside option. Q.E.D.

\section{Appendix B: A Non-Cooperative Bargaining Model with Outside and Inside Options}

We consider an alternating-offer bargaining game with the following features. Time proceeds in equally spaced periods of length $z>0$, which are denoted by $h=0,1$, and so on. Buyers and suppliers are eager to avoid delay as they discount payoffs. We could incorporate different sharing rules by letting $S$ and the various buyers $B^{i}$ have different interest rates. As discussed in the main text, lacking a theory of how size affects buyers' impatience and thus their respective discount factors, we choose for all players the same interest rate $r>0$. Bargaining proceeds pairwise, i.e., between $I$ buyers and $I$ agents of the same supplier $S$. As we will focus on the limit where $z \rightarrow 0$, it is without consequences that we let suppliers' agents make the first proposal in $h=0$.

We now express supply relations as infinite flows of quantities and transfers. ${ }^{43}$ This ensures that if there is delay with one buyer, other firms can already start to purchase and sell. Otherwise, i.e., in a model with a one-shot purchase and sale decision, the delay of one buyer would hold up purchases and sales by all other buyers, which seems artificial. ${ }^{44}$ Hence, if the supplier produces the constant flow quantity $q$, then its flow costs are $c q$. Likewise, $R(\cdot)$ denotes now the flow of revenues, while a contract specifies the fixed flow of transfers $\tau^{i}$ together with the

\footnotetext{
${ }^{43}$ Our set-up borrows from the large literature on worker-firm bargaining the representation of the "bargaining pie" as a flow of future payoffs and the availability of an alternative option during (temporary) disagreement. The seminal papers are Haller and Holden (1990) and Fernandez and Glazer (1991). Importantly, however, in these models one party (the union) must also undertake a costly action (such as a strike) during temporary breakdown, which is a source of multiple equilibria and potential delay.

${ }^{44}$ As buyers compete downstream, in a one-shot model it would indeed be necessary that buyers "wait" until each of them has come to an agreement with the supplier. Note also that with frictions coming from delay, it would also not help to allocate a given "time window" to the negotiation process, right after which all purchases and sales must be made. In this case, rejecting an offer to make a counteroffer would not add to the total delay until which transactions can be consumed. (Such a time window could, however, "work" in a model where frictions come from an exogenous risk of breakdown between an offer and a counteroffer. As noted already previously, however, this seems not to be a reasonable assumption for professional negotiations.)
} 
variable flow $q w^{i}{ }^{45}$

The model incorporates both inside and outside options. In a period $h$ where no agreement has been reached so far but where also no side has yet walked away from the negotiations, a buyer has the inside option to purchase at the flow costs $c_{I n}$. If instead the outside option is taken up after disagreement, $B^{i}$ can instantaneously rely on a supply at marginal $\operatorname{costs} c_{\text {Out }}^{i}$, but has to incur the respective (discounted) costs $F+K_{B}\left(\Delta_{B}^{i}\right) \cdot{ }^{46}$ We still define $V_{I n}^{i}$ as in (9), though this is now in flow terms. On the other hand, the outside option is stated as the discounted value of the future stream of payoffs with

$$
v_{\text {Out }}^{i}:=\max _{\Delta_{B}^{i}}\left\{\frac{1}{r} n^{i} \max _{q}\left[R\left(q, q_{S}\right)-\left(\bar{c}_{\text {Out }}-\Delta_{B}^{i}\right) q\right]-K_{B}\left(\Delta_{B}^{i}\right)-F\right\} .
$$

In what follows, we focus on equilibria where all negotiations lead to an immediate agreement. We comment below on how this is restrictive. The net surplus in each bilateral negotiation is again $n^{i}\left[R\left(q_{S}, q_{S}\right)-c q_{S}\right]-V_{I n}^{i}$, though this is now in terms of flows. As $z \rightarrow 0$, we find that the surplus is split equally given that both sides are equally impatient. This together with $w^{i}=c$, which is again intuitive as the argument for Lemma 1 carries over, pins down $\tau^{i}$ for each $B^{i}$, that is unless $\tau^{i}$ is determined by the binding outside option of $B^{i}$.

Proposition B1. The non-cooperative bargaining game has a unique equilibrium without delay. All contracts specify $w^{i}=c$, while as $z \rightarrow 0$ all $\tau^{i}$ are determined as follows. If

$$
\frac{1}{2}\left[n^{i}\left[R\left(q_{S}, q_{S}\right)-c q_{S}\right]+V_{I n}^{i}\right] \frac{1}{r} \geq V_{\text {Out }}^{i},
$$

then $\tau^{i}$ satisfies

$$
\tau^{i}=\frac{1}{2} n^{i}\left[R\left(q_{S}, q_{S}\right)-q_{S} c\right]-\frac{1}{2} V_{I n}^{i}
$$

Otherwise, we have that

$$
\tau^{i}=n\left[{ }^{i} R\left(q_{S}, q_{S}\right)-q_{S} c\right]-r V_{\text {Out }}^{i}
$$

\footnotetext{
${ }^{45}$ We allow firms in the Cournot game to adjust quantities instantaneously and focus on the competitive (Markov) equilibrium. Results would be unaffected if firms could only adjust quantities each period $h$ or if they had to fix quantities once and for all after deciding which source of supply to use. Off equilibrium, i.e., when there is delay with $B^{i}$ or when the two sides have split up unsuccessfully, all firms that are not controlled by $B^{i}$ will still choose $q_{S}$. This can be supported by beliefs that attribute any other observable quantity choice (or a change in price) to a temporary deviation by the respective firm and not to a break-up of negotiations with the respective buyer. (Note that as long as a final break-up is not directly observable, other beliefs may create incentives to "game" competitors' beliefs by choosing quantities other than the one-shot Cournot levels. We must leave an analysis of such beliefs to further studies.)

${ }^{46}$ It is straightforward to incorporate some fixed real time $Z>0$ that it could take to build up own production facilities.
} 
Proof. The proof is kept short as we can apply both some of our previous arguments from the main text as well as standard arguments from the bargaining literature. Given that we focus on equilibria without delay, in a bilateral negotiation between an agent of $S$ and $B^{i}$ we can take all contracts with buyers $B^{j}$ and $j \neq i$ as given. Also, as already argued for Lemma 1, the agreement with $B^{i}$ has no implication for the supplier's payoff from all other buyers $B^{j}$. Consequently, we can consider the negotiations with $B^{i}$ completely in isolation, which then allows us to draw on results from standard bilateral alternating-offer bargaining. ${ }^{47}$

There is a unique (subgame perfect) pair of offers that are made by $B^{i}$ and $S$ respectively, whenever it is their turn to move (though, in equilibrium, the game will end in $h=0$ with the immediate acceptance of the supplier's offer). Both offers are efficient in that they specify $w^{i}=c$. Denote the transfer offered by the buyer by $\tau_{B}^{i}$ and that offered by the supplier by $\tau_{S}^{i}$. The respective offer makes the other side just indifferent between acceptance and rejection. We first ignore the outside option. Then, the buyer's alternative is to rely on its inside option for one (more) period and offer $\tau_{B}^{i}$ in the next period, which the supplier will accept. The buyer's discounted value of using the inside option over a period of time $z$ equals $\left(1-e^{-r z}\right) / r$ times $V_{I n}^{i}$ (as defined in (9)). Hence, $\tau_{B}^{i}$ and $\tau_{S}^{i}$ are determined by the two indifference conditions for the buyer and the supplier

$$
\begin{aligned}
\frac{1}{r} n^{i}\left[R\left(q_{S}, q_{S}\right)-c q_{S}-\tau_{S}^{i}\right] & =\frac{1-e^{-r z}}{r} V_{I n}^{i}+\frac{e^{-r z}}{r} n^{i}\left[R\left(q_{S}, q_{S}\right)-c q_{S}-\tau_{B}^{i}\right] \\
\frac{1}{r} \tau_{B}^{i} & =\frac{e^{-r z}}{r} \tau_{S}^{i}
\end{aligned}
$$

respectively. Solving out and taking limits for $z \rightarrow 0$ yields $\tau_{B}^{i} \rightarrow \tau^{i}$ and $\tau_{S}^{i} \rightarrow \tau^{i}$, where $\tau^{i}$ is given by (26). Finally, if $\tau_{S}^{i}$ does not match the value of the buyer's outside option, then in the unique equilibrium $\tau^{i}=\tau_{S}^{i}$ is determined by (27). ${ }^{48}$ Q.E.D.

To see that the characterization in Proposition 4, which also includes the inside option but relies on the axiomatic Nash approach, is identical to that in Proposition B1, note that the instantaneous flow payoff is just equal to $r$ times the discounted value of all future payoffs.

\footnotetext{
${ }^{47}$ See Rubinstein (1982) for the seminal paper on the open-horizon alternating-offer game.

${ }^{48}$ There is no need to take the limit as we specified that a buyer who decides to quit negotiations can take up its outside option immediately.
} 
Applying this to the flows of revenues $R(\cdot)$, costs $c q$, and fixed transfers $\tau^{i}$ transforms (25)-(27) into (11)-(13) and vice versa.

We finally comment on why there may also exist other sequential equilibria of the game. First, the repeated interaction in the markets would allow for collusive equilibria, while we focused on the Cournot outcome. Second, delaying individual agreements may serve as a means to overcome the supplier's opportunism problem. Precisely, if we restrict ourselves to longterm non-renegotiated contracts, then it may be possible to circumvent the non-observability of contracts by delaying an agreement with, say, buyer $B^{i}$ for one period so that the quantity choices of all other buyers $B^{j}$ or the respective prices (credibly) communicate the respective variable components $w^{j} .{ }^{49}$ A detailed analysis of such equilibria is beyond this paper, but may offer new insights in the scope of the opportunism problem..$^{50}$

\section{Appendix C: Calculations for the Numerical Example}

We first restate some well known results for the two-firm linear Cournot model. If both firms purchase at constant marginal costs $c$, they choose the quantities $q_{S}=(a-c) /(3 b)$ and realize per-firm profits $(a-c)^{2} /(9 b)$. If we fix the output of one firm at $q_{S}$, then the other firm optimally chooses $q=(a-\widehat{c}) /(2 b)-q_{S} / 2$ if it has marginal input costs $\widehat{c}$. The profits for the latter firm are then $(2 a-3 \widehat{c}+c)^{2} /(36 b)$, where we substituted for $q_{S}$.

Following disagreement, $B^{i}$ chooses $\Delta_{B}^{i}$ to maximize

$$
n^{i} \frac{\left(2 a-3 c_{\text {Out }}^{i}+c\right)^{2}}{36 b}-\frac{1}{2} \gamma_{B}\left(\Delta_{B}^{i}\right)^{2},
$$

where $c_{\text {Out }}^{i}=\bar{c}_{\text {Out }}-c_{\text {Out }}^{i}$. This expression is strictly concave whenever $n^{i}<2 b \gamma_{B}$. The firstorder condition yields a solution with $c_{\text {Out }}^{i}<\bar{c}_{\text {Out }}$ for all feasible $c$ whenever $\bar{c}_{\text {Out }}<2 a / 3$, while the solution satisfies $c_{\text {Out }}^{i}>0$ for all $c$ whenever

$$
\left(2 a+\bar{c}-3 \bar{c}_{O u t}\right) n^{i}<\bar{c}_{O u t}\left(6 b \gamma_{B}-3 n^{i}\right) .
$$

\footnotetext{
${ }^{49}$ It is important to note, however, that the outcome in Proposition A1 does constitute an equilibrium as under the (rational) expectations that there is immediate agreement to a contract with $w^{j}=c$ in all other bilateral negotiations an immediate agreement to $w^{i}=c$ is also the (unique) equilibrium outcome in negotiations with $B^{i}$.

${ }^{50}$ In the considered dynamic environment market foreclosure may also be achieved by building reputation through the repeated use of short-term contracts. See Hart (1995) for an argument along these lines.
} 
For $\bar{c}=\bar{c}_{O u t}=a / 2$ condition (28) is satisfied whenever $n^{i}<2 b \gamma_{B}$. Solving for the first-order condition yields

$$
\Delta_{B}^{i}=\frac{\left(2 a+c-3 \bar{c}_{O u t}\right) n^{i}}{6 b \gamma_{B}-3 n^{i}},
$$

which can be substituted into the objective function for $B^{i}$ to yield

$$
V_{\text {Out }}^{i}=\frac{n^{i}}{18} \frac{\gamma_{B}(c+a / 2)^{2}}{2 b \gamma_{B}-n^{i}} .
$$

Using Proposition 1 and the derived expressions, the outside option of all buyers binds whenever

$$
\frac{n^{i}}{18} \frac{\gamma_{B}(c+a / 2)^{2}}{2 b \gamma_{B}-n^{i}}>n^{i} \frac{(a-c)^{2}}{9 b} \frac{1}{2},
$$

which given the restriction to values $0 \leq c \leq a / 2$ holds if and only if

$$
\Delta_{S}<\widehat{\Delta}_{S}:=\frac{a}{2} \frac{3 \bar{n}-4 b \gamma_{B}+3 \sqrt{b \gamma_{B}\left(2 b \gamma_{B}-\bar{n}\right)}}{b \gamma_{B}-\bar{n}} .
$$

Note also that $0<\widehat{\Delta}_{S}<a / 2$ holds from $n^{i} \leq N<\gamma_{B} b$.

If all buyers' outside option binds, we have that

$$
U=N \frac{(a-c)^{2}}{9 b}-\frac{1}{2} \gamma_{S}\left(\Delta_{S}\right)^{2},
$$

which is strictly concave if $N<9 b \gamma_{S} / 2$ and which has the solution

$$
\Delta_{S}^{*}=a \frac{N}{9 b \gamma_{S}-2 N},
$$

satisfying $0<\Delta_{S}^{N B}<a / 2$ if $N<9 b \gamma_{S} / 4{ }^{51}$

If buyers' outside option binds, then we have with $n^{i}=\bar{n}$ that

$$
U=2 N \frac{(a-c)^{2}}{9 b}-\frac{N}{9}(a / 2+c)^{2} \frac{\gamma_{B}}{2 b \gamma_{B}-\bar{n}}-\frac{1}{2} \gamma_{S}(a / 2-c)^{2},
$$

where the first-order condition yields

$$
\Delta_{S}^{* *}=a\left[\frac{1}{2}-\frac{\frac{9}{2} \gamma_{S} b-N \frac{5 \gamma_{B} b-4 \bar{n}}{2 b \gamma_{B}-\bar{n}}}{9 \gamma_{S} b-N \frac{6 b \gamma_{B}-4 \bar{n}}{2 b \gamma_{B}-\bar{n}}}\right]
$$

We have $0<\Delta_{S}^{* *}<a / 2$ if

$$
N<b \gamma_{S} \frac{9}{2} \frac{2 b \gamma_{B}-\bar{n}}{9 b \gamma_{B}-4 \bar{n}}
$$

\footnotetext{
${ }^{51}$ Note that we do not claim here that $\Delta_{S}^{*}>\widehat{\Delta}_{S}$.
} 
while $U$ is now strictly concave if

$$
N<b \gamma_{S} \frac{9}{2} \frac{2 b \gamma_{B}-\bar{n}}{3 b \gamma_{B}-4 \bar{n}}
$$

which is weaker than (29). Moreover, after some transformations we have that (29) is satisfied for all $\bar{n} \leq N$ if $N<3 b \gamma_{S} .^{52}$

Summing up, there are only three potential solutions to the problem in stage one: $\widehat{\Delta}_{S}, \Delta_{S}^{*}$, and $\Delta_{S}^{* *}$. The numerical calculations for the parameters chosen in the example in the main text show that both $\Delta_{S}^{*}$ and $\Delta_{S}^{* *}$ are not relevant as both $\Delta_{S}^{*}<\widehat{\Delta}_{S}$ and $\Delta_{S}^{* *}>\widehat{\Delta}_{S}$ such that optimally $\Delta_{S}=\widehat{\Delta}_{S}$. That is, as depicted in Figure 1 the solutions lie at the kink.

\section{References}

Berto Villas-Boas, S. (2004), Vertical Contracts between Manufacturers and Retailers: Inference with Limited Data, mimeo.

Binmore, K., Rubinstein, A., and Wolinsky, A. (1986), The Nash Bargaining Solution in Economic Modelling, Rand Journal of Economics 17, 176-188.

Binmore, K., Shaked, A., and Sutton, J. (1989), An Outside Option Experiment, Quarterly Journal of Economics 104, 73-770.

Bonnet, C., Dubois, P., and Simioni, M. (2004), Two-part Tariffs vs. Linear Pricing between Manufacturers and Retailers: Empirical Tests on Differentiated Product Markets, mimeo.

Chae, S. and Heidhues, P. (2004), Buyers' Alliances for Bargaining Power, Journal of Economics and Management Strategy 13, 731-754.

Chen, Z. (2003), Dominant Retailers and the Countervailing-Power Hypothesis, Rand Journal of Economics 34, 612-625.

Chen, Z. (2004), Countervailing Power and Product Diversity, mimeo.

Chipty, T. and Snyder, C.M. (1999), The Role of Outlet Size in Bilateral Bargaining: A Study of the Cable Television Industry, Review of Economics and Statistics 81, 326-340.

\footnotetext{
${ }^{52}$ Note that we do not claim here that $\Delta_{S}^{* *}<\widehat{\Delta}_{S}$.
} 
Chiu, S. (1998), Noncooperative Bargaining, Hostages, and Optimal Asset Ownership, American Economic Review 88, 882-901.

Competition Commission (2000), Supermarkets: A Report on the Supply of Groceries from Multiple Stores in the United Kingdom, Report Cm-4842.

DeGraba, P. (2003), Quantity Discounts from Risk Averse Sellers, mimeo, FTC.

DeMeza, D. and Lockwood, B. (1998), Does Asset Ownership Always Motivate Managers? Outside Options and the Property Rights Theory of the Firm, Quarterly Journal of Economics 113, 361-386.

Dobson, P. and Waterson, M. (1997), Countervailing Power and Consumer Prices, Economic Journal 107, 418-430.

European Commission (1999), Buyer Power and its Impact on Competition in the Food Retail Distribution Sector of the European Union, Report produced for the European Commission, DG IV, Brussels.

FTC (2001), Report on the Federal Trade Commission Workshop on Slotting Allowances and Other Marketing Practices in the Grocery Industry, Report by the Federal Trade Commission Staff, Washington, D.C.

Fernandez, R. and Glazer, J. (1991), Striking a Bargain between two Completely Informed Agents, American Economic Review 81, 240-252.

Haller, H. and Holden, S. (1990), A Letter to the Editor on Wage Bargaining, Journal of Economic Theory 52, 232-236.

Fumagalli, C. and Motta, M. (2000), Buyers' Coordination, mimeo.

Hart, M. (1995), Market Foreclosure without Vertical Integration, Economics Letters 47, 423429.

Hart, O. (1995), Firms, Contracts, and Financial Structure, Oxford University Press, Oxford.

Hart, O. and Tirole, J. (1990), Vertical Integration and Market Foreclosure, Brooking papers on Economic Activity: Microeconomics, 205-85. 
Horn, H. and Wolinsky, A. (1988), Bilateral Monopolies and Incentives for Merger, Rand Journal of Economics, 408-419.

Inderst, R. and Shaffer, G., Retail Mergers, Buyer Power, and Product Variety, forthcoming Economic Journal.

Inderst, R. and Wey, C. (2004), Buyer Power and Supplier Incentives, mimeo, LSE.

Inderst, R. and Shaffer, G. (2005), The Role of Buyer Power in Merger Control, manuscript prepared for the new ABA Handbook.

Katz, M.L. (1987), The Welfare Effects of Third Degree Price Discrimination in Intermediate Goods Markets, American Economic Review 77, 154-167.

Mazzarotto, N. (2003), Retail Mergers and Buyer Power, mimeo.

McAfee, R.P. and Schwartz, M. Opportunism in Multilateral Vertical Contracting: Nondiscrimination, American Economic Review 84, 210-230.

Nordemann, J. (1995), Buying Power and Sophisticated Buyers in Merger Control Law: The Need for a More Sophisticated Approach, European Competition Law Review 5, 270-281.

O'Brien, D.P. and Shaffer, G. (1994), The Welfare Effects of Forbidding Discriminatory Discounts: A Secondary Line Analysis of Robinson-Patman, Journal of Law, Economics \& Organization 10, 296-317.

OECD (1999), Buying Power of Multiproduct Retailers, Series Roundtables on Competition Policy DAFFE/CLP(99)21, OECD, Paris.

Pitofsky, R. (1997), Thoughts on "Leveling the Playing Field" in Health Care Markets, Federal Trade Commission (February 13, 1997), Washington D.C.

Qiu, L.D., 1997, On the Dynamic Efficiency of Bertrand and Cournot Equilibria, Journal of Economic Theory 75, 213-229.

Rubinstein, A., 1982, Perfect Equilibrium in a Bargaining Model, Econometrica 50, 97-109.

Schmidt, K., 1997, Managerial Incentives and Product Market Competition, Review of Economic Studies 64, 191-213. 
Shaked, A. and Sutton, J. (1984), Involuntary Unemployment as a Perfect Equilibrium in a Bargaining Model, Econometrica 52, 1351-1364.

Snyder, C.M. (1996), A Dynamic Theory of Countervailing Power, Rand Journal of Economics 27, 747-769.

Snyder, C.M. (2005), Countervailing Power, manuscript prepared for the New Palgrave Dictionary.

Steptoe, M. (1993), The Buyer-Power Defense in Merger Cases, Antitrust Law Journal 61, 493-505.

Vives, X. (1999), Oligopoly Pricing, MIT Press, Cambidge Mass.

von Ungern-Sternberg, T. (1996), Countervailing Power Revisited, International Journal of Industrial Organization 14, 507-520. 